\title{
MIT physicists attack proposed MX missile system
}

THE new MX missile system, currently under study by the US Defense Department as a possible replacement for the silo-based Minuteman missiles, has been criticised for being too costly, while remaining vulnerable to Soviet attack, by a group of scientists from the Massachusetts Institute of Technology.

The scientists also claim that the MX ("missile experimental") system, which seeks to protect the missiles from attack by placing them in tunnels 10 to 12 miles long in which they can rapidly change firing position, is also likely to create "insuperable arms control problems."

Preliminary studies for the MX system, whose development could it is claimed cost up to $\$ 30$ billion, were begun by the Defense Department in 1974. And the Pentagon has recently informed 10 Western states that they are being screened as possible deployment sites.

Criticism of the proposed system was made in a report published last week by MITs Program in Science and
Technology for International Security. The authors of the report are Dr Michael B. Callaham, a research associate with PSTIS, Dr Bernard Feld, professor of physics and director of PSTIS, Dr E. Hadjimichael, professor of physics at Fairfield University in Connecticut, and Dr Kosta M. Tsipis, associate director of PSTIS.

The scientists point out that although, until recently, silo-based missiles had been relatively well protected from a surprise Soviet attack, the greater accuracy and explosive power of a new class of ICBM's deployed by the USSR have removed this invulnerability, leading to the MX proposal.

However, the report says that as the MX tunnels would be built to withstand a much lower pressure than the present silos, and would still provide a limited target, a Soviet strike would have little difficulty in destroying the command and control systems.

Furthermore, while accepting that the MX missile would give the US a powerful and accurate intercontinental ballistic missile, the scientists claim that it would be detrimental to arms control since the uncertainties to which it could give rise might lead the Soviets to adopt a "launch on warning" policy, or even to refuse to accept further limitations on new ICBMs.

As an alternative to the tunnelbased system, the authors suggest that the administration should examine the possibilities for a highly mobile system - perhaps using missiles launched from aircraft or helicopters-which would both permit escape from Soviet attack, and be relatively easy to verify quantitatively by spy satellites.

The Defense Department is already thought to be having second thoughts about the MX system, partly as the result of the technical weaknesses that are being pointed out. Last autumn Defense Secretary Harold Brown decided to delay moving the system into full-scale development, even though Congress has already approved expenditure of up to $\$ 481$ million.

David Dickson

\section{Hazards of non-nuclear energy}

AT A time when the hazards of nuclear power are under discussion as part of the general debate on energy futures, the UK Health and Safety Commission (HSC) has brought out a report which turns attention to the hazards associated with what it calls the "conventional sources of energy": coal, gas, oil and water.

The report sets out to answer 32 questions put to Tony Benn, the Secretary of State for Energy early last year. The questions came in two letters from representatives of the Staff Associations and Trade Unions at the UK Atomic Energy Authority's (UKAEA) Dounreay Experimental Research Establishment (DERE) in the North of Scotland. A similar report was prepared last year by the Nuclear Installations Inspectorate (NII) of the HSC on 'Some aspects of the safety of nuclear installations in Great Britain'. That report was also initiated by $\mathrm{Mr}$ Benn, who asked the NII to answer questions on the health and safety aspects of nuclear power put by himself, Nigel Forman MP and the Friends of the Earth. Many of the questions from DERE are along the same lines as those put to the NII.

The HSC's report attempts to "set the individual questions asked in perspective against the background of the conventional energy industry as a whole". It considers the production and processing of the conventional energy sources up to the point when energy, most commonly in the form of electricity, leaves the producer for

\begin{tabular}{llc}
\hline $\begin{array}{l}\text { Energy } \\
\text { source }\end{array}$ & operation & Deaths/GWy \\
\hline Coal & Extraction & 1.4 \\
& Transport & 0.2 \\
Total & Generation & 0.2 \\
Oil and gas & Extraction & 1.8 \\
& Transport & 0.3 \\
Total & Generation & Insignificant \\
Nuclear & Extraction & 0.3 \\
& Transport & 0.1 \\
& Generation and & Insignificant \\
& reprocessing & 0.15 \\
\hline Total & & \\
\hline
\end{tabular}

Estimated number of deaths due to accidents per GWy (a) of electrical energy sent out

the user.

The HSC found it impossible to identify accidents associated with the transportation of fuel oil to power stations. It has, however, managed to discuss transportation of other fuel including coal, but it is careful to point out that "meaningful statistics are difficult to obtain".

Nevertheless, the report does attempt to discuss many of the hazards of energy production, while warning that its figures are preliminary and should not be taken too literally. The coal-based energy industry poses by far the greatest occupational hazard. UK coal miners suffer many more accidents and are more susceptible to occupational diseases, namely pneumoconiosis, than other energy workers. 64 people were killed in 1975 out of a total workforce of 250,000 in the coal mining industry. There were 586 serious accidents and 53,898 accidents involving more than three days absence from work.

The transport of liquefied natural gas (LNG), liquefied petroleum gas (LPG) and chlorine (used in power stations) are among the greatest conventional hazards. Because these are all kept under pressure, rupture of the pressure vessel containing them could result in a large release of dangerous gas. In the case of LNG and LPG the danger would be from a massive explosion. In the event of a release of chlorine, the danger would stem from the toxic properties of the gas. Similar accidents, causing as many as 1,000 deaths, could happen if storage tanks failed at a power station.

The report concludes by attempting to make a comparison of the hazards associated with the different energy sources-but it baulks at the task. HSC claims that it cannot compare non-fatal accidents or non-fatal occupational diseases, because of inconsistent reporting procedures. The final, very tentative comparison is therefore made on the basis of fatal accidents resulting from routine operations. The effects of severe rare accidents are not included because "the probability of these events is so small that they would have no significant effect on the long-term averages". On this very tentative basis nuclear power turns out to be the least hazardous energy source.

Judy Redfearn 